\title{
Attitudes among hospital physicians to the reporting of adverse drug reactions in Sweden
}

\author{
Elisabet Ekman • M. Bäckström
}

Received: 4 December 2007 / Accepted: 29 August 2008 / Published online: 30 September 2008

(C) Springer-Verlag 2008

\begin{abstract}
Objectives This study was designed to investigate attitudes to and incentive for reporting adverse drug reactions (ADRs) in general and towards nurses as reporters of ADRs in particular in a sample of hospital physicians.

Method A questionnaire was sent to 1,201 randomly selected hospital physicians.

Results The main factors for the decision to report an ADR were the severity of the reaction, a reaction to a new drug, and an unusual reaction. The most important factor for refraining from reporting was that the reaction was well known. There were no significant differences between males and females or between age groups in these aspects. A majority were positive or neutral to nurses as reporters. Only $6 \%$ stated that their willingness to report ADRs would be affected in a negative way if nurses were involved in the program for reporting.

Conclusions The results of this survey showed that inclusion of hospital nurses as reporters will not decrease the reporting rate from the physicians.
\end{abstract}

Keywords Adverse drug reaction - Spontaneous reporting · Hospital physicians $\cdot$ Attitudes $\cdot$ Nurses

E. Ekman $(\bowtie)$

Regional Pharmacovigilance Unit, Clinical Pharmacology,

University Hospital,

S-221 85 Lund, Sweden

e-mail: Elisabet.Ekman@skane.se

M. Bäckström

Division of Clinical Pharmacology, University Hospital of Umeå,

Umeå, Sweden

\section{Introduction}

Spontaneous reporting of adverse drug reactions (ADRs) is one of the basic methods for post-marketing surveillance and is a method to generate signals of unrecognized ADRs [1]. Withdrawals due to safety problems are often based on data from spontaneous reporting systems [2].

In Sweden it is mandatory for health-care professionals to report serious ADRs, unexpected ADRs, and all side effects related to the use of new drugs, except for those labelled as common in the Summary of Product Characteristics (SPC). The Swedish authority responsible for medical products (MPA) has defined health-care professionals as physicians, dentists, prescribing nurses, and nurses working in children's and school health care (Medical Products Agency's Code of Statutes. LVFS 2001:12).

From an international perspective, the reporting rate of ADRs in Sweden has always been high [1]. In 2004, Sweden received 465 reports per million inhabitants, the highest reporting rate in the European Community (EU) (Assessment of the European Community System of Pharmacovigilance, final report 25 January 2006). The reporting rate in 2005 was on the same level, and in 2006 a total of 5,130 reports were sent from health-care professionals to the MPA or its regional centres (RC) (http://www. lakemedelsverket.se/Tpl/NewsPage__6036.aspx), giving a reporting rate of 563 per million inhabitants. Two thousand and twenty-two (43\%) of the reports came from hospital physicians, and of those, 1,444 (65\%) were assessed as serious. Six hundred (27\%) of the reports from physicians contained an ADR that was not listed in the SPC 
(unlisted). However, we know that there is an extensive degree of underreporting. Swedish studies have shown an underreporting rate of $86-100 \%$ of thrombosis/pulmonary embolism, for example [3, 4].

To increase reporting, it has been suggested that hospital nurses should be included in the reporting scheme. However, the attitude among physicians to this and their own willingness to report, if nurses were also allowed to report, have been debated.

The purpose of this study is to investigate physicians' knowledge of and attitudes towards reporting of ADRs. We also wanted to study physicians' attitudes to nurses as autonomous reporters.

Finally, we wanted to study whether there were any statistical differences in physicians' attitudes to nurses as reporters based on age or gender.

\section{Method}

A sample of 1,201 of the 24,500 hospital physicians working in Sweden was randomly selected. A questionnaire was sent in May 2006 in a personally addressed letter to the physicians, of whom 717 were identified as males, 481 as females, and 3 could not be defined with certainty in this respect. The questionnaire was followed by a reminder with a second copy of the questionnaire 2 weeks later. Since the questionnaire was to be answered anonymously, the second questionnaire was sent out to all recipients.

The questionnaire was divided into five parts: (1) demographic factors, (2) general questions about ADR reporting and factors relevant to the decision to report or refrain from reporting a suspected ADR, (3) methodological incentives to improve reporting (electronically, directly via the patient's record, simplified reporting form, reporting without a form, reporting by phone), (4) attitudes towards nurses as autonomous reporters, and (5) interest in receiving feed-back information for reported ADRs.
To test the feasibility of the questionnaire, a pilot test was performed. The Statistical Package for Social Science (SPSS) was used for the statistical analysis. The chi-square test was used to establish possible significant differences. A $P$-value $<0.05$ was considered as significant.

\section{Results}

Of the 1,201 questionnaires dispatched, 6 were excluded as they were inadequately filled in and 3 were returned due to unknown addresses. Six hundred and fifty-two responded giving a total response rate of $54 \%$. The response rate for males was $51 \%$, and $57 \%$ of the females answered the questionnaire. Eleven (2\%) did not state their sex, and in 14 (2\%) questionnaires, information about age was missing. On average, the responders had worked 21 years in their profession, and their median age was 49 years. Two hundred and fifty (38\%) stated that they had never reported a suspected ADR, whereas 385 (59\%) had reported at least once in their career; reponses to this question were missing in $17(3 \%)$ of the questionnaires.

A severe reaction, a reaction to a new drug, and an unusual reaction were the most important factors for the decision to report a suspected ADR (Table 1). Among those who responded to our questionnaire who had never reported an ADR, the most important factors that would motivate the reporting of an ADR in the future would be a reaction to a new drug $26(10 \%)$ or an unusual reaction 23 (9\%). The most important factor for refraining from reporting was that the reaction was well-known (Table 2). There were no significant differences between males and females or between age groups in these aspects. Among nonreporters, $80(32 \%)$ stated that difficulties in reporting only on suspicion were a reason to refrain from reporting, and $70(28 \%)$ answered that they were uncertain of how to report. In the group of reporters, $32(8 \%)$ were uncertain of how to report.

Table 1 Factors important for determining whether or not to report an adverse drug reaction

\begin{tabular}{|c|c|c|c|c|c|c|c|}
\hline & \multicolumn{2}{|l|}{ Male } & \multicolumn{2}{|l|}{ Female } & \multicolumn{2}{|l|}{ Total } & \multirow{2}{*}{$\begin{array}{l}P- \\
\text { value }\end{array}$} \\
\hline & $\begin{array}{l}\text { Number } \\
(n=365)\end{array}$ & Percentage & $\begin{array}{l}\text { Number } \\
(n=276)\end{array}$ & Percentage & $\begin{array}{l}\text { Number } \\
(n=652)^{\mathrm{a}}\end{array}$ & Percentage & \\
\hline The severity of the reaction & 198 & 54.2 & 170 & 61.6 & 368 & 56.4 & 0.06 \\
\hline A new drug & 205 & 56.2 & 157 & 56.9 & 362 & 55.5 & 0.8 \\
\hline Unusual reaction & 188 & 51.5 & 150 & 54.3 & 338 & 51.8 & 0.4 \\
\hline The reaction is not labelled & 131 & 35.9 & 96 & 34.8 & 227 & 34.8 & 0.7 \\
\hline Certainty that the reaction is really due to an ADR & 89 & 24.4 & 76 & 27.5 & 165 & 25.3 & 0.9 \\
\hline The reaction is labelled & 35 & 9.6 & 25 & 9.1 & 60 & 9.2 & 0.8 \\
\hline
\end{tabular}

${ }^{a}$ Those who did not state their sex are included in this total 
Table 2 Factors important for refraining from reporting an adverse drug reaction

\begin{tabular}{|c|c|c|c|c|c|c|c|}
\hline & \multicolumn{2}{|l|}{ Male } & \multicolumn{2}{|l|}{ Female } & \multicolumn{2}{|l|}{ Total } & \multirow{2}{*}{$\begin{array}{l}P- \\
\text { value }\end{array}$} \\
\hline & $\begin{array}{l}\text { Number } \\
(n=365)\end{array}$ & Percentage & $\begin{array}{l}\text { Number } \\
(n=276)\end{array}$ & Percentage & $\begin{array}{l}\text { Number } \\
(n=652)^{\mathrm{a}}\end{array}$ & Percentage & \\
\hline The reaction is already well known & 255 & 69.9 & 194 & 70.3 & 449 & 68.9 & 0.9 \\
\hline Never suspected any ADR & 96 & 26.3 & 57 & 20.7 & 154 & 23.6 & 0.4 \\
\hline Forgetfulness & 90 & 24.7 & 69 & 25.0 & 159 & 24.4 & 0.6 \\
\hline Difficulties in reporting only on suspicion & 79 & 21.6 & 64 & 23.2 & 143 & 21.9 & 0.2 \\
\hline Lack of time & 78 & 21.4 & 69 & 25.0 & 147 & 22.5 & 0.3 \\
\hline Uncertain of how to report & 55 & 15.1 & 49 & 17.8 & 104 & 16.0 & 0.4 \\
\hline
\end{tabular}

${ }^{a}$ Those who did not state their sex are included in this total

More than half of the questionnaire responders, 346 (53\%) stated that allowing suspected ADRs to be reported using a web-based system would improve the overall reporting rate. Reporting directly from the patient's case record was preferred by 250 (38\%), and 220 (34\%) stated that sending copies of the patient's records without a reporting form would facilitate reporting. About one-fourth, 169 (26\%), would appreciate the option to report by telephone. The corresponding numbers among nonreporters were $138(55 \%), 93(37 \%), 64(26 \%)$, and $71(20 \%)$, respectively. There were no significant differences between younger and older physicians in this part of the questionnaire.

Five hundred and eighteen (79\%) stated that they would like a feed-back letter containing the causality assessment, and only $11(2 \%)$ declared that they did not want any feed-back.

Almost half of the questionnaire responders stated that they saw nurses as reporters of ADRs in a positive way (Table 3). Younger physicians were significantly more negative to this than their older colleagues. Thirty-nine $(6 \%)$ believed that their willingness to report would be affected in a negative way if nurses were also included as reporters. There were no significant differences between age groups or gender in this question.

\section{Discussion}

The response rate to our questionnaire was reasonable and similar to that found in other studies [5-7]. A limitation of this type of study is the low response rate. With a higher response rate it would have been possible to draw more certain conclusions. Females answered the questionnaire to a higher degree than their male colleagues.

Almost $60 \%$ had reported an ADR at least once in their career. This is a high figure compared with a similar study performed in the Netherlands in 1997 in which only $43 \%$ had ever reported to the national reporting centre [8]. Nearly $40 \%$ in our study stated that they had never reported any suspected ADRs. If one were to transfer these figures to all hospital physicians in Sweden this would give a number of around 10,000 nonreporters. This may be an underestimation as those who responded to the questionnaire may be more prone to report ADRs.

The most common factors identified for reporting an ADR were a severe reaction and a reaction to a new drug. This is in accordance with the reporting rules and with other studies [5-7]. The result is also in accordance with the reporting in Sweden, where $65 \%$ of reports from physicians during 2006 were serious. One-third of the responders stated that an unlabelled reaction was an important factor

Table 3 Number of responders who viewed nurses as reporters of adverse drug reactions in a positive/negative way, arranged by age group

\begin{tabular}{|c|c|c|c|c|c|c|c|}
\hline & \multicolumn{6}{|l|}{ Age group } & \multirow[t]{3}{*}{$P$-value } \\
\hline & \multicolumn{2}{|l|}{49 and younger } & \multicolumn{2}{|l|}{50 and older } & \multicolumn{2}{|l|}{ Total } & \\
\hline & Number $(n=301)$ & Percentage & Number $(n=323)$ & Percentage & Number $(n=638)^{\mathrm{a}}$ & Percentage & \\
\hline Positive & 131 & 43.5 & 173 & 53.6 & 309 & 48.4 & $0.01 *$ \\
\hline Neither/nor & 66 & 21.9 & 71 & 22.0 & 144 & 22.6 & 0.9 \\
\hline Negative & 104 & 34.6 & 79 & 24.5 & 185 & 29.0 & $0.006^{*}$ \\
\hline
\end{tabular}

${ }^{\mathrm{a}}$ Those who did not state their age are included in this total

$* P<0.05$ 
for reporting and one-fourth of the reports from physicians in 2006 contained an unlisted reaction. This is important as this is the best way to generate signals of new ADRs. The most common reason not to report was that the ADR was already well-known. Our finding is in line with other studies $[5,6,8]$. Another problem identified was how and when to report. Uncertainty on the reporting rules was greater among nonreporters. However, the response rate to our questions from nonreporters was low, which makes it difficult to draw any certain conclusions from this group.

We found no differences between genders in the questions about factors important for the decision to report (Tables 1 and 2). This is in line with a study from the Netherlands where no significant difference based on age and gender was found when Dutch physicians were asked for the assumed reporting rate for 16 hypothetical ADRs [8].

Our study indicates that feed-back, including some kind of causality assessment, is important. This was confirmed by another Swedish study [9]. An international study by Biriell et al. [10] identified follow-up information as an important reason for reporting. A feed-back letter with an assessment of the causality between the reported ADR and the drug(s) is sent to the reporters in Sweden. It is possible that this could be one of the reasons for the high reporting rate.

It has been debated whether physicians' willingness to report will decrease if all nurses are included in the reporting scheme. In our study only $6 \%$ believed that their reporting rate would be affected in a negative way. This result is in agreement with the findings from a study conducted in Sweden that showed that the reporting rate from physicians did not decrease when nurses also reported ADRs [11]. However, we were surprised to find that younger physicians were significantly more negative to nurses as reporters compared to their older colleges.

Starting in April 2007, the MPA in Sweden has included all nurses in the reporting scheme. Hopefully the inclusion of nurses and education in pharmacovigilance for both nurses and physicians will increase the reporting of suspected ADRs and decrease the number of nonreporters. In the future, we hope that other methods for reporting ADRs, for example web-based methods and reporting integrated in the patient's record, will further increase the reporting rate. As withdrawals due to safety problems, signals of new ADRs, and risk factors for ADRs are often based on spontaneous reports, this will enhance the overall safety of drugs.

\section{Conclusion}

The results of this survey show that hospital physicians regard the severity of the reaction to be the most important factor for reporting and that underreporting could be reduced if a web-based system for reporting was introduced. Inclusion of hospital nurses as reporters will not decrease the reporting rate from the physicians.

Acknowledgements We wish to thank the participating physicians for answering the questionnaires, Tom Mjörndal for valuable comments on the manuscript, Anders Sundström for help with the statistics, and Bengt Lindeskog for linguistic comments.

\section{References}

1. Wiholm B-E, Olsson S, Moore N, Waller P (2000) Spontaneous reporting systems outside the US. In: Strom B (ed) Pharmacoepidemiology, 3rd edn. John Wiley, New York, pp 175-192

2. Olivier P, Montastruc JL (2006) The nature of the scientific evidence leading to drug withdrawals for pharmacovigilance reasons in France. Pharmacoepidemiol Drug Saf 15(11):808-812

3. Samuelsson E, Hägg S, Bäckström M, Granberg K, Mjörndal T (1996) Thrombosis caused by oral contraceptives. Underreporting to the adverse effects registry. Läkartidningen 93(37):3117-3118, 3121-3114

4. Bäckström M, Mjörndal T, Dahlqvist R (2004) Under-reporting of serious adverse drug reactions in Sweden. Pharmacoepidemiol Drug Saf 13(7):483-487

5. Bäckström M, Mjörndal $T$, Dahlqvist R, Nordkvist-Olsson $T$ (2000) Attitudes to reporting adverse drug reactions in northern Sweden. Eur J Clin Pharmacol 56(9-10):729-732

6. Hasford J, Goettler M, Munter KH, Muller-Oerlinghausen B (2002) Physicians' knowledge and attitudes regarding the spontaneous reporting system for adverse drug reactions. J Clin Epidemiol 55(9):945-950

7. Cosentino M, Leoni O, Banfi F, Lecchini S, Frigo G (1997) Attitudes to adverse drug reaction reporting by medical practitioners in a Northern Italian district. Pharmacol Res 35(2):85-88

8. Eland IA, Belton KJ, van Grootheest AC, Meiners AP, Rawlins MD, Stricker BH (1999) Attitudinal survey of voluntary reporting of adverse drug reactions. Br J Clin Pharmacol 48(4):623-627

9. Wallerstedt SM, Brunlöf G, Johansson ML, Tukukino C, Ny L (2007) Reporting of adverse drug reactions may be influenced by feedback to the reporting doctor. Eur J Clin Pharmacol 63(5):505508

10. Biriell C, Edwards IR (1997) Reasons for reporting adverse drug reactions-some thoughts based on an international review. Pharmacoepidemiol Drug Saf 6(1):21-26

11. Bäckström M, Ekman E, Mjörndal T (2007) Adverse drug reaction reporting by nurses in Sweden. Eur J Clin Pharmacol 63(6):613-618 